\title{
Cell Blood Count Alterations and Patterns of Anaemia in Autoimmune Atrophic Gastritis at Diagnosis: A Multicentre Study
}

\author{
Marco Vincenzo Lenti ${ }^{1,+}(\mathbb{D})$, Edith Lahner ${ }^{2,+}{ }^{\text {, Gaetano Bergamaschi }}{ }^{1}$ (D), Emanuela Miceli ${ }^{1}$, \\ Laura Conti $^{2}$, Sara Massironi ${ }^{3}{ }^{(\mathbb{D}}$, Sara Cococcia $^{1}\left(\mathbb{D}\right.$, Alessandra Zilli $^{3}$, Flavio Caprioli ${ }^{3}$, \\ Maurizio Vecchi ${ }^{3}$, Stefania Maiero ${ }^{4}$, Renato Cannizzaro ${ }^{4}{ }^{\mathbb{D}}$, Gino Roberto Corazza ${ }^{1}$, \\ Bruno Annibale ${ }^{2}$ and Antonio Di Sabatino ${ }^{1, *(D)}$ \\ 1 First Department of Medicine, Istituto di Ricovero e Cura a Carattere Scientifico San Matteo Hospital \\ Foundation, University of Pavia, Piazzale Golgi 19, 27100 Pavia, Italy; marco.lenti@unipv.it (M.V.L.); \\ n.bergamaschi@smatteo.pv.it (G.B.); e.miceli@smatteo.pv.it (E.M.); sara.cococcia@gmail.com (S.C.); \\ gr.corazza@smatteo.pv.it (G.R.C.) \\ 2 Department of Surgical-Medical Sciences and Translational Medicine, Digestive and Liver Disease Unit, \\ Sant'Andrea Hospital, Sapienza University of Rome, 00185 Roma, Italy; edith.lahner@uniroma1.it (E.L.); \\ lau88conti@gmail.com (L.C.); bruno.annibale@uniroma1.it (B.A.) \\ 3 Department of Gastroenterology and Endoscopy, IRCCS Ca' Granda Foundation, University of Milan, \\ 20122 Milano, Italy; sara.massironi@policlinico.mi.it (S.M.); alessandra.zilli86@gmail.com (A.Z.); \\ flavio.caprioli@unimi.it (F.C.); maurizio.vecchi@unimi.it (M.V.) \\ 4 Oncological Gastroenterology Unit, Centro di Riferimento Oncologico di Aviano (CRO) IRCCS, \\ 33081 Aviano, Italy; smaiero@cro.it (S.M.); rcannizzato@cro.it (R.C.) \\ * Correspondence: a.disabatino@smatteo.pv.it; Tel.: +39-038-2502-973; Fax: +39-038-2502-618 \\ + Joint co-first authors.
}

Received: 19 October 2019; Accepted: 12 November 2019; Published: 15 November 2019

\begin{abstract}
Background: Autoimmune atrophic gastritis (AAG) leads to iron and/or vitamin B12 malabsorption, with subsequent haematological alterations which could represent the sole clinical manifestation. We aimed to assess patterns of anaemia and micronutrient deficiencies in patients with AAG at the time of diagnosis. Methods: Observational, multicentre, cross-sectional study including consecutive adult patients diagnosed with AAG within the last ten years. Cell blood count, red cell distribution width, serum vitamin B12, and ferritin were collected. Multivariate analysis for predictive factors of anaemia was computed. Results: 654 AAG patients (mean age $59.2 \pm 13.8$ years, female $(\mathrm{F})$ : male $(\mathrm{M})$ ratio $=2.3: 1)$ were included. Anaemia was present in 316 patients $(48.3 \%$; mean age $60.1 \pm 15.8$ years, F:M ratio = 2.3:1). Pernicious anaemia $(132 / 316$ cases, $41.7 \%)$ was more common in males $(27.1 \%$ versus $12.4 \% ; p=0.001)$ and in older patients $(63.0 \pm 14.6$ versus $58.9 \pm 14.9$ years; $p=0.014)$, while iron deficiency anaemia (112/316 cases, $35.4 \%)$ was more common in females ( $16.9 \%$ versus $10.0 \%$; $p=0.039)$ and in younger patients ( $56.8 \pm 16.6$ versus $60.2 \pm 14.6$ years; $p=0.043)$. The prevalence of iron deficiency was equally distributed between anaemic and non-anaemic patients $(p=0.9)$. Anisocytosis (odds ratio: 10.65, 95\% confidence interval: $6.13-18.50, p<0.0001$ ) was independently associated with anaemia. Conclusions: Anaemia is a common manifestation in AAG patients, mostly due to micronutrient deficiencies. Scant haematologic alterations and micronutrient deficiencies may precede overt anaemia.
\end{abstract}

Keywords: anisocytosis; iron deficiency; pernicious anaemia; vitamin B12

\section{Introduction}

Autoimmune atrophic gastritis (AAG) is an organ-specific, immune-mediated disorder that affects the corpus and fundus of the stomach, causing atrophy of the oxyntic mucosa, impaired 
gastric acid secretion, and intrinsic factor deficiency [1,2]. AAG is a relatively frequent condition, particularly in elderly individuals, even if any age group may be affected [3-5]. In the natural history of AAG, malabsorption of micronutrients, especially vitamin B12 and iron, occurs over time [6,7]. Micronutrient deficiencies lead to various manifestations, in particular, red blood cell alterations, which may represent the sole clinical presentation of AAG [4-8]. A diagnosis of AAG can be easily made in case of overt pernicious anaemia $[9,10]$. However, according to a previous study of ours [4], a considerable proportion of AAG patients have scant and subtle haematological alterations, including isolated mean corpuscular volume (MCV) changes and isolated increase of red cell distribution width (RDW). A high proportion of AAG patients may also suffer from iron deficiency anaemia long before the onset of vitamin B12 deficiency, or may present a dimorphic anaemia as a consequence of combined deficiency [6]. According to previous observational studies, the prevalence of anaemia in patients with AAG ranges from $19 \%$ to $94 \%$ (Table 1) [4,6,11-18]. However, despite the relevant clinical burden, ad hoc studies focusing on red blood cell alterations in large cohorts of patients with histologically-confirmed AAG are lacking. As we have recently shown, haematological alterations might be overlooked, especially in female patients and in non-haematological settings, determining substantial AAG diagnostic delay [18,19].

Table 1. Main studies reporting the prevalence of anaemia in adult patients with autoimmune atrophic gastritis (AAG).

\begin{tabular}{|c|c|c|c|c|c|c|c|c|c|}
\hline Authors & Year & Setting & Patients (n) & $\begin{array}{l}\text { Enrolled } \\
\text { at AAG } \\
\text { Diagnosis }\end{array}$ & $\begin{array}{l}\text { Mean } \\
\text { Age } \\
\text { (years) }\end{array}$ & $\begin{array}{l}\text { Overall } \\
\text { Anaemia } \\
\text { (\%) }\end{array}$ & PA (\%) & IDA (\%) & Major Findings \\
\hline Burman et al. [11] & 1991 & $\begin{array}{l}\text { Internal } \\
\text { medicine }\end{array}$ & 86 & Yes & 56 & 80.2 & 80.2 & NA & $\begin{array}{l}\text { High PCA levels } \\
\text { associated with PA }\end{array}$ \\
\hline Hersko et al. [6] & 2006 & Haematology & 160 & NS & 59 & 75.0 & 18.1 & 51.8 & $\begin{array}{l}\text { Microcytic anaemia } \\
\text { more common } \\
\text { in younger age }\end{array}$ \\
\hline Lahner et al. [12] & 2009 & Gastroenterology & 165 & Yes & 54 & 94.5 & 49.0 & 45.5 & $\begin{array}{c}\text { PCA and anti-intrinsic } \\
\text { factor antibodies yield } \\
73 \% \text { accuracy PA } \\
\text { diagnosis }\end{array}$ \\
\hline Miceli et al. [4] & 2012 & Gastroenterology & 99 & Yes & 58 & 59.6 & 59.6 & 0 & $\begin{array}{c}\text { PA was the most } \\
\text { common cause of AAG } \\
\text { diagnosis }\end{array}$ \\
\hline Lahner et al. [13] & 2015 & Gastroenterology & 83 & Yes & 59 & 51.8 & 51.8 & NA & $\begin{array}{c}\text { A genetic variant } \\
\text { of transcobalamin } 2 \text { was } \\
\text { related to PA }\end{array}$ \\
\hline Zhang et al. [14] & 2017 & Gastroenterology & 275 & Yes & 61 & 19.3 & 5.4 & 8.4 & $\begin{array}{c}\text { No clear gender } \\
\text { differences; microcytic } \\
\text { anaemia more common } \\
\text { in younger age }\end{array}$ \\
\hline Kalkan et al. [15] & 2017 & Gastroenterology & 355 & NS & 57 & 30.1 & 30.1 & NA & $\begin{array}{l}\text { PA more common } \\
\text { in older patients }\end{array}$ \\
\hline Carabotti et al. [16] & 2017 & Gastroenterology & 379 & Yes & 55 & 88.4 & 53.6 & 34.8 & $\begin{array}{l}\text { PA more frequent } \\
\text { in patients without } \\
\text { gastrointestinal } \\
\text { symptoms }\end{array}$ \\
\hline Villanacci et al. [17] & 2017 & Pathology & 138 & NS & 48 & 54.7 & 25.0 & 29.7 & $\begin{array}{l}\text { IDA more common } \\
\text { than PA }\end{array}$ \\
\hline Lenti et al. [18] & 2019 & Gastroenterology & 291 & Yes & 60 & 49.5 & 23.4 & 11.7 & $\begin{array}{l}\text { Isolated MCV alterations } \\
\text { associated with greater } \\
\text { AAG diagnostic delay }\end{array}$ \\
\hline
\end{tabular}

Abbreviations: IDA, iron deficiency anaemia; MCV, mean corpuscular volume; NA, not assessed; NS, not specified; PA, pernicious anaemia; PCA, anti-parietal cell antibody. Studies exploring atrophic gastritis prior to $H$. pylori discovery were not included. Mean age refers to anaemic patients only, whenever this datum is available.

On these bases, the primary aim of this cross-sectional study was to assess the prevalence and types of anaemia and micronutrient deficiencies, according to age and gender, in AAG patients at the time of diagnosis. The secondary aim was to identify patterns of red blood cell alterations and putative predictors of anaemia. Lastly, recovery from anaemia at a one-year follow-up was evaluated in a subgroup of AAG patients. 


\section{Materials and Methods}

\subsection{Participating Centres, Patient Selection, and Definition of Anaemia}

Four Italian, tertiary referral centres for the diagnosis and management of AAG participated in this study (Istituto di Ricovero e Cura a Carattere Scientifico San Matteo Hospital in Pavia, Sant'Andrea Hospital in Rome, IRCCS Ca' Granda Hospital in Milan, and IRCCS National Cancer Institute in Aviano). In these centres, most Italian adult AAG patients are referred and followed-up. Each centre has a dedicated database in which relevant data, including sociodemographic characteristics and medical history, have been prospectively collected from all consecutive adult AAG patients over the last ten years. According to internationally agreed criteria, AAG diagnosis was based on histological grounds following the updated Sydney-Houston criteria [20]. The presence of AAG-related serum antibodies, namely anti-parietal cell antibodies (PCA) and anti-intrinsic factor antibodies, was not considered a necessary feature in case of clear and undoubted histological lesions [21]. In fact, these antibodies have no absolute accuracy for AAG, and may not be present in late disease stage [12,22,23] In all cases, gastric biopsy specimens were reviewed from expert gastrointestinal pathologists. Histopathological alterations consistent with any stage of AAG include: (i) atrophy of gastric oxyntic mucosa, (ii) absence of atrophy in gastric antrum mucosa, (iii) concurrent evidence of extensive intestinal and/or pseudopyloric metaplasia, and (iv) hyperplasia of gastrin-producing cells and hyperplasia of enterochromaffin-like cells. Patients with uncertain AAG diagnosis (e.g., patchy or uncertain mucosal lesions), active H. pylori infection, atrophic pangastritis, and with incomplete medical history, were not included in the study. All data from adult ( $\geq 18$ years old) AAG patients were anonymised and collated onto a predefined spreadsheet. All queries regarding uncertain data were resolved via email or meetings through consensus with the study coordinators (MVL, EL). Particularly, demographic and clinical data from patients' medical records were collected and analysed, including gender, age, main clinical presentation, comorbidities, and histopathological features according to Operative Link on Gastritis Assessment (OLGA) and Operative Link on Gastric Intestinal Metaplasia Assessment (OLGIM) [24,25]. Relevant laboratory data at the time of AAG diagnosis ( \pm 1 month) were collected, including haemoglobin, MCV (normal range 80-98 femtoliter), RDW (normal range 11-15\%), platelets (normal range 150,000-450,000/microliter), serum vitamin B12 (deficient if $<200 \mathrm{ng} / \mathrm{L}$ ), iron (deficient if $<55 \mathrm{ng} / \mathrm{mL}$ ), ferritin (deficient if $<30 \mathrm{ng} / \mathrm{mL}$ ), folate (deficient if $<4 \mathrm{ng} / \mathrm{mL}$ ), homocysteine (increased if $>12 \mu \mathrm{mol} / \mathrm{L}$ ), and presence or absence of serum PCA [26]. Complete blood counts were performed by a Cell-Dyn Sapphire. Vitamin B12 was assessed in serum by an automated immunochemistry analyser, which is a solid-phase, competitive chemiluminescent enzyme immunoassay. PCA were detected by either immunofluorescence or enzyme-linked immunosorbent assay (ELISA) techniques. Iron, ferritin, and folate were detected by a colorimetric assay. Homocysteine was assessed with a fluorometric assay kit in plasma or serum. Anaemia was classified according to the World Health Organisation (WHO), i.e., haemoglobin $<120 \mathrm{~g} / \mathrm{L}$ in females and $<130 \mathrm{~g} / \mathrm{L}$ in males living at sea level [27]. Transferrin, reticulocytes, inflammatory markers (e.g., $C$ reactive protein), and urine methylmalonic acid were not included in the final analyses, as they were missing in many patients. Iron deficiency anaemia was defined as the presence of anaemia and low iron and ferritin levels, while pernicious anaemia was defined as the presence of macrocytic anaemia (or normocytic in case of dimorphic anaemia) and vitamin B12 and/or folate deficiency. Anaemia of chronic disease was inferred in case of ferritin $>100 \mathrm{ng} / \mathrm{mL}$ and iron $<55 \mathrm{ng} / \mathrm{mL}$. A few patients with concomitant haematological disorders were excluded a priori, as it was not possible to ascertain the aetiology of red blood cell alterations. In a subgroup of 181 patients belonging to the Pavia cohort, for whom cell blood count was available after 12 months since diagnosis, one-year follow-up data were reported. The study was approved by each local Ethics Committee and all patients gave their informed consent for the anonymised publication of data. The results of this study are reported according to the STrengthening the Reporting of OBservational studies in Epidemiology (STROBE) recommendations. 


\subsection{Statistical Analysis}

A descriptive statistical analysis was performed for clinical features, and data were expressed as number of total and/or percentage or mean \pm standard deviation (SD). Some variables were not available for all records, and these were excluded for percentage calculation. Comparison amongst groups at univariate analysis was performed by Chi-squared test. Multivariate logistic regression analyses were used to identify variables related to the dependent variables of interest (any type of anaemia, pernicious anaemia, and iron deficiency anaemia) by including as cofactors all demographic, haematological, and clinical variables of interests. For the logistic regression model, the overall model fit was considered (significant difference of the null model -2 Log Likelihood and the full model -2 Log Likelihood by Chi-Squared test), and the Hosmer and Lemeshow test, a statistical test for goodness of fit for the logistic regression model, was performed, with a $p$-value $<0.05$ indicating poor fit and a $p$-value $>0.05$ indicating a good logistic regression model fit. Each logistic regression model was run by using the methods "Enter", "Forward", "Backward", and "Stepwise" to enter the independent variables into the model. Variables were removed if $p>0.1$. Associations of cofactors with the independent variable were taken into consideration when statistical significance was present in all models and were expressed by odds ratio (OR) and 95\% confidence intervals (95\% CI). The Chi-squared test was performed between age groups and gender, and within age groups. Two-tailed $p$ values less than 0.05 were considered statistically significant. Statistical analyses were performed with a dedicated software (MedCalc Software, Mariakerke, Belgium, version 12.7.8).

\section{Results}

\subsection{Demographic, Clinical, and Histopathological Characteristics}

A computerised database with records of 817 patients was initially set up (Figure 1). After a careful review, 163 patients were excluded because they did not match the inclusion criteria or because of missing data. Thus, the total number of enrolled patients was 654 (mean age $59.2 \pm 13.8$ years, female: male ratio $=2.3: 1$, for whom at least the baseline complete cell blood count and clinical presentation were available. Other variables were not available for all patients, hence statistical analyses were preformed after exclusion of patients with missing data, as detailed in the tables. Of these, 287 patients (43.9\%) were from Pavia, 268 (41.0\%) from Rome, 74 (11.3\%) from Milan, and 25 (3.8\%) from Aviano. Relevant demographic and clinical data are reported in Table 2. Indeed, more than one sign, symptom, or alteration may have occurred in the same patient. Female gender was predominant, and 470 patients $(71.8 \%)$ were aged $>50$ years. No statistical difference emerged between male and female gender when plotted according to age groups. 295 patients (46.8\%) suffered from another concomitant autoimmune disease, which was autoimmune thyroid disease in most cases (251 patients; $39.9 \%$ ). Other less common autoimmune diseases included type 1 diabetes, vitiligo, psoriasis, coeliac disease, and primary biliary cholangitis. According to the Sydney-Houston criteria, the mean severity score of corpus atrophy (information available for 549/654 patients) was $2.6 \pm 0.6$. Operative Link on Gastritis Assessment (OLGA) scores 1 and 2 were observed in $52(9.4 \%)$ and 497 (90.5\%) patients, respectively. Gastric corpus intestinal metaplasia was present in $437(79.6 \%)$ patients, with a mean severity score of $1.2 \pm 0.8$, whereas Operative Link on Gastric Intestinal Metaplasia Assessment (OLGIM) scores 1, 2, and 3 were present in $208(37.8 \%), 225$ (40.9\%), and 4 (0.7\%) patients, respectively. Pseudopyloric metaplasia was seen in $409(62.5 \%)$ patients. 


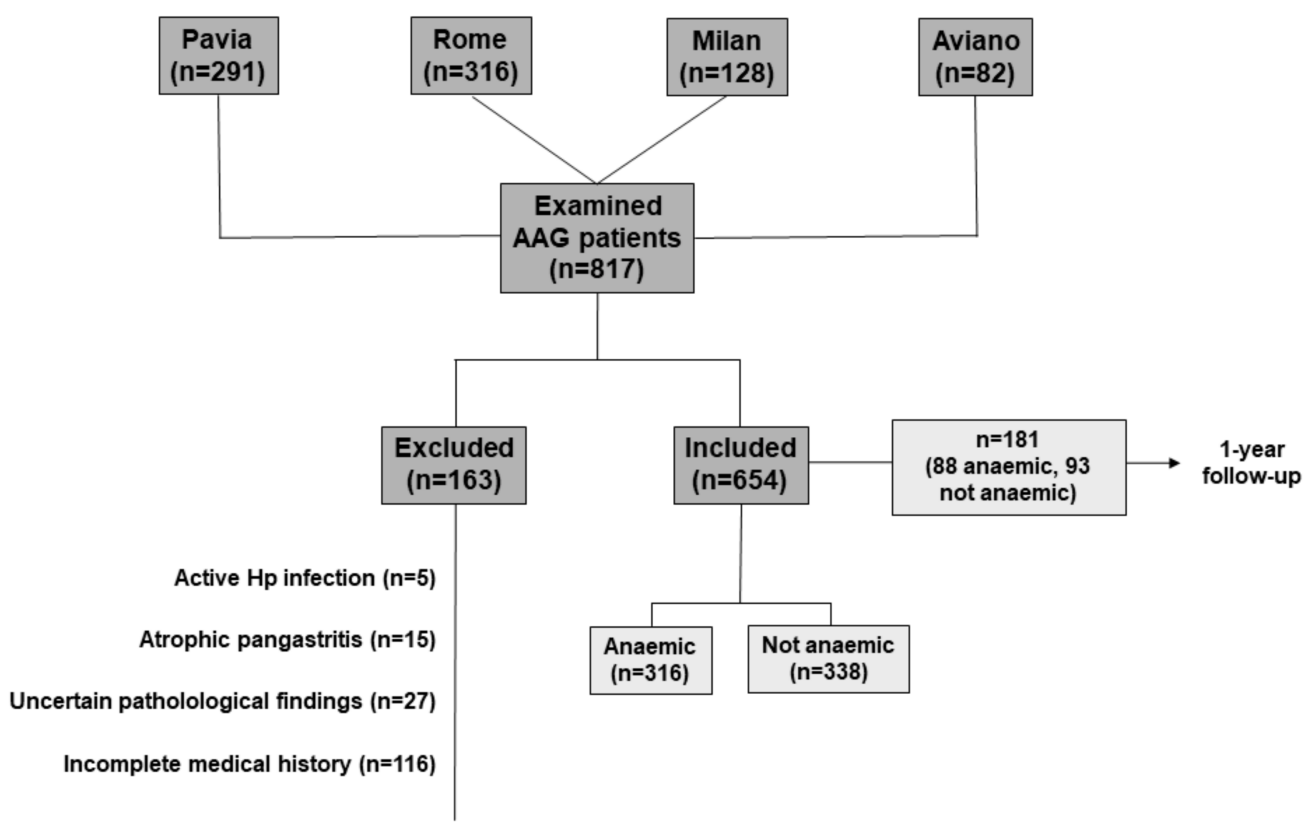

Figure 1. Flowchart of the study. Patients were excluded as per study design. Of the 654 included patients, cell blood count data of 181 (88 anaemic, 93 not anaemic) patients at one-year follow-up were reported. Abbreviations: AAG, autoimmune atrophic gastritis; Hp, H. pylori.

Table 2. Main demographic and clinical features of patients with autoimmune atrophic gastritis (AAG).

\begin{tabular}{cc}
\hline Demographic Features & \\
\hline Total AAG patients, $n$ & 654 \\
Females, $n(\%)$ & $459(70.2)$ \\
Age (years), median (range) & $61(18-88)$ \\
Main clinical presentation at diagnosis, $n(\%)$ & \\
Haematological & $368(56.3)$ \\
Gastrointestinal & $109(16.7)$ \\
Neuropsychiatric & $105(16.1)$ \\
Endocrinological & $23(3.5)$ \\
Miscellaneous & $53(8.1)$ \\
Current or past smoking & \\
Cardiovascular disease & $246(37.7)$ \\
Autoimmune comorbidities & $384(58.7)$ \\
Neuropsychiatric disorders & $305(46.7)$ \\
Family history of AAG & $180(27.5)$ \\
Other relevant clinical information, & $55(8.4)$ \\
Family history of gastric cancer & $16(2.4)$ \\
Proton pump inhibitor use prior to diagnosis & $237(36.3)$ \\
Previously treated $H$. pylori infection & $97(14.8)$ \\
\hline
\end{tabular}

\subsection{Haematological Alterations}

Haematological alterations were the leading cause of AAG diagnosis (Table 2). Overall, the mean haemoglobin level was $116 \pm 26 \mathrm{~g} / \mathrm{L}$, the mean MCV was $90.7 \pm 16 \mathrm{fL}$, and the mean RDW was $15.9 \% \pm 4.3 \%$. The mean platelet count was $236.9 \pm 95.4 /$ microliter, while thrombocytopenia or thrombocytosis were observed in $92(15.2 \%)$ and in $13(2.1 \%)$ patients, respectively. Anaemia, which was observed in 316 patients (48.3\%; mean age $60.1 \pm 15.8$ years, F:M ratio $=2.3: 1$ ), was mild (haemoglobin $\geq 95 \mathrm{~g} / \mathrm{L}$ ) in 194 patients (61.4\%), moderate (haemoglobin 80-94 g/L) in 52 patients $(16.4 \%)$, and severe (haemoglobin $<80 \mathrm{~g} / \mathrm{L})$ in 70 patients $(22.2 \%)$. Figure 2 reports the proportion of patients with and without anaemia (A), according to MCV (B), and subtypes of anaemia (C). Patients with anaemia had a significantly higher prevalence of MCV abnormalities, anisocytosis, vitamin B12 
and folate deficiency, and thrombocytopenia in comparison to non-anaemic patients. Table 3 reports all relevant demographic, clinical, haematological, and histological variables of AAG patients according to the presence or absence of anaemia (any type). With regards to non-anaemic patients, MCV and RDW alterations were present in $76(23.9 \%)$ and in 113 (39.1\%) cases, respectively. A significantly higher prevalence of gastrointestinal symptoms, autoimmunity, and treated H. pylori infection was also seen in non-anaemic compared to anaemic patients (Table 3).
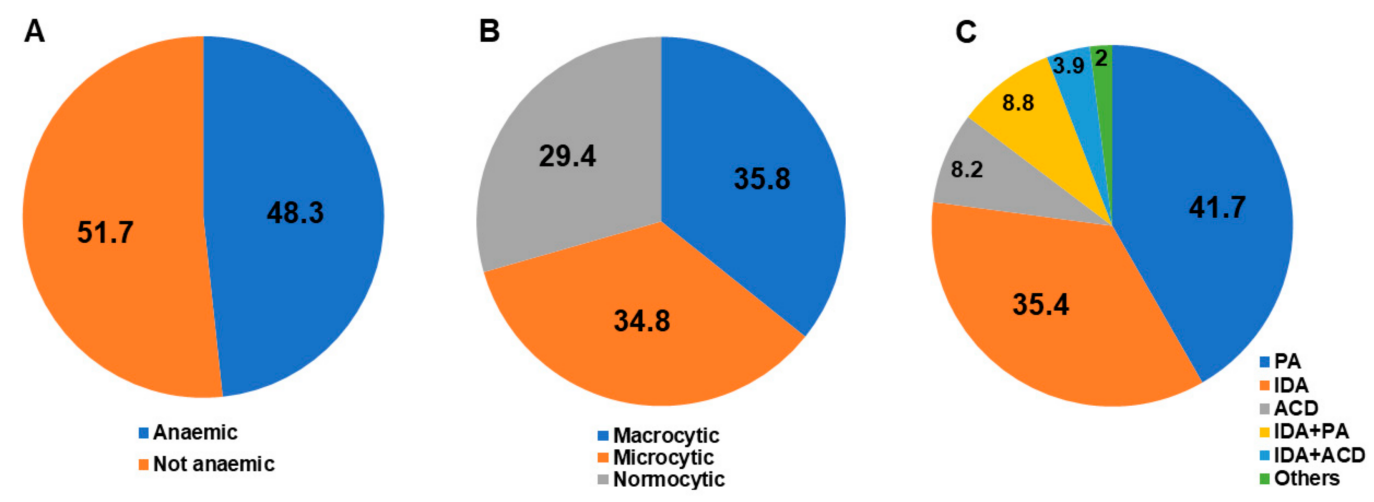

Figure 2. The study population includes 654 adult patients suffering from autoimmune atrophic gastritis. The figure shows the proportion of patients with and without anaemia (A), the distribution of mean corpuscular volume (MCV) in anaemic patients (B), and subtypes of anaemia (C). The category "Others" includes chronic kidney failure and neoplastic diseases. Abbreviations: ACD, anaemia of chronic disease; IDA, iron deficiency anaemia; PA, pernicious anaemia.

Table 3. Clinical, haematological, and histological variables of patients with autoimmune atrophic gastritis (AAG) according to the presence or absence of anaemia (any type).

\begin{tabular}{|c|c|c|c|}
\hline & Presence of Anaemia & Absence of Anaemia & $p$-Value \\
\hline Female gender & $220 / 459(47.9)$ & $239 / 459(52.1)$ & 0.8916 \\
\hline Male gender & $96 / 195(49.2)$ & $99 / 195(50.8)$ & 0.9563 \\
\hline Age (years) mean $\pm \mathrm{SD}$ & $60.1 \pm 15.8$ & $59.3 \pm 13.9$ & 0.5061 \\
\hline \multicolumn{4}{|l|}{ Age groups (years) } \\
\hline$\geq 80$ & $31(10.0)$ & $10(3.0)$ & \multirow{7}{*}{ Trend 0.5463} \\
\hline $70-79$ & $74(23.9)$ & $82(24.8)$ & \\
\hline $60-69$ & $64(20.6)$ & $89(26.8)$ & \\
\hline $50-59$ & $47(15.2)$ & $73(22.0)$ & \\
\hline $40-49$ & $61(19.7)$ & $41(12.3)$ & \\
\hline $30-39$ & $24(7.7)$ & $32(9.6)$ & \\
\hline$\leq 29$ & $9(2.9)$ & $5(1.5)$ & \\
\hline Current or past smoking & $103 / 300(34.3)$ & $114 / 324(35.2)$ & 0.8894 \\
\hline Gastrointestinal symptoms & $32 / 302(10.6)$ & $75 / 310(24.2)$ & $<0.0001$ \\
\hline Endocrinological disorders & $7 / 302(2.3)$ & $16 / 312(5.1)$ & 0.1050 \\
\hline Cardiovascular disease & $178 / 301(59.1)$ & $188 / 317(59.3)$ & 0.9674 \\
\hline Neuropsychiatric disorders & $80 / 297(26.9)$ & $90 / 313(28.7)$ & 0.6816 \\
\hline Autoimmune comorbidities & $130 / 305(42.6)$ & $165 / 325(50.8)$ & 0.0491 \\
\hline Autoimmune thyroid disease & $108 / 303(35.6)$ & $143 / 325(44.0)$ & 0.0399 \\
\hline
\end{tabular}


Table 3. Cont.

\begin{tabular}{|c|c|c|c|}
\hline & Presence of Anaemia & Absence of Anaemia & $p$-Value \\
\hline Family history of AAG & $19 / 296(6.4)$ & $33 / 314(10.5)$ & 0.1136 \\
\hline Family history of gastric cancer & $6 / 296(2.0)$ & $9 / 314(2.9)$ & 0.6838 \\
\hline PPI use prior to diagnosis & $63 / 216(29.2)$ & $97 / 223(43.5)$ & 0.0025 \\
\hline Previous H. pylori infection & $26 / 276(9.4)$ & 61/311 (19.6) & 0.0008 \\
\hline Macrocytosis & $108 / 303(35.6)$ & $48 / 317(15.1)$ & $<0.0001$ \\
\hline Microcytosis & 105/303 (34.6) & 28/317 (8.8) & $<0.0001$ \\
\hline Normocytosis & 90/303 (29.7) & $241 / 317(76.0)$ & $<0.0001$ \\
\hline Vitamin $\mathrm{B}_{12}$ deficiency & $167 / 278(60.1)$ & $124 / 303(40.9)$ & $<0.0001$ \\
\hline Iron deficiency & $163 / 280(58.2)$ & $164 / 286(57.3)$ & 0.9007 \\
\hline Folate deficiency & $24 / 165(14.5)$ & $10 / 201(4.9)$ & 0.0031 \\
\hline Vitamin $B_{12}$ and iron deficiency & $72 / 263(27.4)$ & $64 / 279(22.9)$ & 0.2749 \\
\hline Increased RDW & 227/277 (81.9) & $113 / 289(39.1)$ & $<0.0001$ \\
\hline Thrombocytopenia & 69/294 (23.5) & $23 / 310(7.4)$ & $<0.0001$ \\
\hline Thrombocytosis & 6/294 (2.0) & $7 / 310(2.2)$ & 0.9231 \\
\hline Intestinal metaplasia & 246/310 (79.3) & 258/332 (77.7) & 0.6814 \\
\hline Pseudopyloric metaplasia & 196/301 (65.1) & $194 / 317(61.2)$ & 0.3547 \\
\hline OLGA 1 & $22 / 269(8.2)$ & $30 / 280(10.7)$ & \multirow{2}{*}{ Trend 0.3851} \\
\hline OLGA 2 & 247/269 (91.8) & $250 / 280(89.3)$ & \\
\hline OLGIM 0 & $56 / 269(20.8)$ & $56 / 280(20.0)$ & \multirow{4}{*}{ Trend 0.6349} \\
\hline OLGIM 1 & $102 / 269(37.9)$ & $106 / 280(37.9)$ & \\
\hline OLGIM 2 & $111 / 269(41.3)$ & $114 / 280(40.7)$ & \\
\hline OLGIM 3 & $0(0)$ & $4 / 280(1.4)$ & \\
\hline
\end{tabular}

Abbreviations: OLGA, Operative Link for Gastritis Assessment; OLGIM, Operative Link on Gastric Intestinal Metaplasia Assessment; PPI, proton pump inhibitor; RDW, red blood cell distribution width; SD, standard deviation. Percentages were calculated after exclusion of patients with missing data. $p<0.0001$ were more frequent in females. Combined pernicious and iron deficiency anaemia was similarly distributed between genders $(13.3 \%$ versus $9.1 \%$; $p=0.1970)$. Thrombocytopenia was nearly two-fold more common in males compared to females ( $21.2 \%$ versus $12.7 \% ; p=0.0108)$. Finally, folate deficiency $(16 \%$ versus $6.5 \% ; p=0.007)$ and hyperhomocysteinaemia $(63.2 \%$ versus $45.9 \% ; p=0.0011$ ) were both more frequent in males.

\subsection{Micronutrient Deficiencies}

Regardless of anaemia, vitamin B12 deficiency was observed in 291 (50.1\%) patients and iron deficiency in 327 (57.8\%) patients. Combined vitamin B12 and iron deficiency was present in $136(25.1 \%)$ cases. Folate deficiency was seen in $34(9.3 \%)$ patients and was associated with vitamin B12 or iron deficiency in $17(2.6 \%)$ and $4(0.6 \%)$ cases, respectively. Folate deficiency anaemia, without concurrent iron or vitamin B12 deficiency, was not observed at all. Patients with anaemia had a significantly higher prevalence of vitamin B12 and folate deficiency compared to non-anaemic patients, while iron deficiency was equally distributed between the two groups (Table 3). Hyperhomocysteinaemia was equally distributed between anaemic and non-anaemic patients (50.6\% versus 51.7; $p=0.778$ ). Regarding non-anaemic patients, at least one micronutrient deficiency was present in 224/338 (66.3\%) cases.

\subsection{Haematological Alterations with Regard to Gender}

In all AAG patients, while normocytosis was equally distributed between genders, microcytosis occurred more frequently in females $(24.0 \%$ versus $15.5 \% ; p=0.0237)$ and macrocytosis more frequently in males $(36.4 \%$ versus $20.3 \% ; p<0.0001)$. Pernicious anaemia $(27.1 \%$ versus $12.4 \% ; p=0.0015)$ and vitamin B12 deficiency without anaemia ( $56.3 \%$ versus $46.8 \% ; p=0.0448)$ were more frequent in males, 
while iron deficiency anaemia $(16.9 \%$ versus $10.0 \% ; p=0.0393)$ and iron deficiency without anaemia $(64.4 \%$ versus $40.9 \%)$ were more frequent in females. Combined pernicious and iron deficiency anaemia was similarly distributed between genders $(13.3 \%$ vs. $9.1 \% ; p=0.1970)$. Thrombocytopenia was nearly twofold more common in males compared to females $(21.2 \%$ vs. $12.7 \% ; p=0.0108)$. Finally, folate deficiency $(16 \%$ vs. $6.5 \% ; p=0.007)$ and hyperhomocysteinaemia $(63.2 \%$ vs. $45.9 \% ; p=0.0011)$ were both more frequent in males.

\subsection{Haematological Alterations with Regard to Age (as a Continuous Variable)}

Overall, AAG patients with microcytosis were younger ( $54.7 \pm 15.5$ versus $61.1 \pm 14.5$ years; $p<0.0001)$, while those with macrocytosis were older $(63.2 \pm 13.8$ versus $58.5 \pm 15.1 ; p=0.0008)$. Patients with iron deficiency anaemia $(56.8 \pm 16.6$ versus $60.2 \pm 14.6$ years; $p=0.0436)$ and combined pernicious and iron deficiency anaemia $(55.9 \pm 15.3$ versus $60.2 \pm 14.9$ years; $p=0.0211)$ were younger, while patients with pernicious anaemia were older $(63.0 \pm 14.6$ versus $58.9 \pm 14.9$ years; $p=0.0144)$. Finally, hyperhomocysteinaemia $(61.3 \pm 15.1$ versus $57.6 \pm 15.2$ years; $p=0.0101)$ was more commonly observed in older patients.

\subsection{Clinical Predictors of Anaemia}

Table 4 shows multivariable results for all possible factors associated with anaemia (any type), pernicious anaemia, and iron deficiency anaemia. At logistic regression analysis, anaemia (any type) was significantly associated with anisocytosis, thrombocytopenia, absence of gastrointestinal symptoms, and no proton pump inhibitor use. Moreover, iron deficiency anaemia was significantly associated with anisocytosis and absence of thrombocytopenia, while pernicious anaemia was significantly associated with anisocytosis, thrombocytopenia, and no history of $H$. pylori infection.

Table 4. Multivariate logistic regression analysis for variables associated with anaemia (any type), iron deficiency anaemia, and pernicious anaemia in patients with autoimmune atrophic gastritis (AAG).

\begin{tabular}{cccc}
\hline Variables & Odds Ratio & $\mathbf{9 5 \%}$ CI & $p$-Value \\
\hline Autoimmune comorbidities & 0.67 & $0.2306-1.9532$ & 0.4644 \\
No history of H. pylori infection & 1.48 & $0.7288-3.0118$ & 0.2775 \\
Thrombocytopenia & 3.27 & $1.4596-7.3507$ & 0.0040 \\
Increased RDW & 10.65 & $6.1381-18.5012$ & $<0.0001$ \\
Absence of gastrointestinal symptoms & 2.26 & $1.1048-4.6312$ & 0.0256 \\
Autoimmune thyroid disease & 0.92 & $0.3127-2.7167$ & 0.8825 \\
Vitamin B12 deficiency & 1.09 & $0.6359-1.8960$ & 0.7371 \\
No PPI use prior to diagnosis & 1.98 & $1.1071-3.5423$ & 0.0213 \\
PCA positivity & 0.92 & $0.4873-1.7438$ & 0.8024 \\
Age < 50 years & 0.67 & $0.3830-1.1922$ & 0.1760 \\
Family history of gastric cancer & 0.45 & $0.0823-2.5594$ & 0.3744 \\
No family history of AAG & 1.77 & $0.7096-4.4185$ & 0.2207 \\
Current or past smoking & 0.78 & $0.4638-1.3122$ & 0.3494 \\
Autoimmune comorbidities & 0.51 & $0.1683-1.5950$ & 0.2517 \\
No history of $H$. pylori infection & 1.69 & $0.8029-3.5970$ & 0.1657 \\
Absence of thrombocytopenia & 2.20 & $1.0789-4.5053$ & 0.0301 \\
Increased RDW & 4.83 & $2.7097-8.6409$ & $<0.0001$ \\
Female gender & 1.47 & $0.8227-2.6430$ & 0.1921 \\
PCA positivity & 1.39 & $0.6535-2.9741$ & 0.3900 \\
Age < 50 years & 0.66 & $0.3372-1.3286$ & 0.2511 \\
No family history of AAG & 1.26 & $0.4861-3.3118$ & 0.6266 \\
Current or past smoking & 1.13 & $0.6082-2.1290$ & 0.6860 \\
Autoimmune comorbidities & 0.60 & $0.1775-2.0391$ & 0.4145 \\
No history of H. pylori infection & 2.98 & $1.1249-7.9012$ & 0.0280 \\
\hline
\end{tabular}


Table 4. Cont.

\begin{tabular}{cccc}
\hline Variables & Odds Ratio & $\mathbf{9 5 \%}$ CI & $p$-Value \\
\hline Thrombocytopenia & 3.51 & $1.7113-7.2044$ & 0.0006 \\
Increased RDW & 6.40 & $3.1210-13.1643$ & $<0.0001$ \\
Female gender & 0.33 & 0.38 to 1.42 & 0.3663 \\
\hline
\end{tabular}

Abbreviations: PCA, anti-parietal cell antibody; RDW, red cell distribution width. The analysis included 549 patients with complete data.

\subsection{Follow-Up of Anaemia}

In a sub-cohort of 181 AAG patients (mean age $59.2 \pm 14.6$ years, F:M ratio = 2.7:1), we compared cell blood count at diagnosis and after treatment of anaemia according to current recommendations [5,7,28]. All patients received parenteral supplementation of vitamin B12 and oral folic acid, and serum levels were normal at one year in all cases. Oral daily iron supplementation with different commercially available formulations was the first-line treatment of iron deficiency, while only three patients required an intravenous formulation. As shown in Figure 3A, a significantly $(p<0.0001)$ lower proportion of anaemic patients was observed at the one-year follow-up in comparison to baseline. Remarkably, stratification of anaemic patients according to MCV significantly $(p=0.003)$ changed after therapy, with complete recovery of macrocytosis (Figure 3B). The proportion of anaemic patients with anisocytosis significantly $(p<0.0001)$ decreased after treatment (Figure 3C). Regarding patients with persistent microcytic anaemia only, this was mild in all cases, with depletion of iron stores despite oral supplementation.

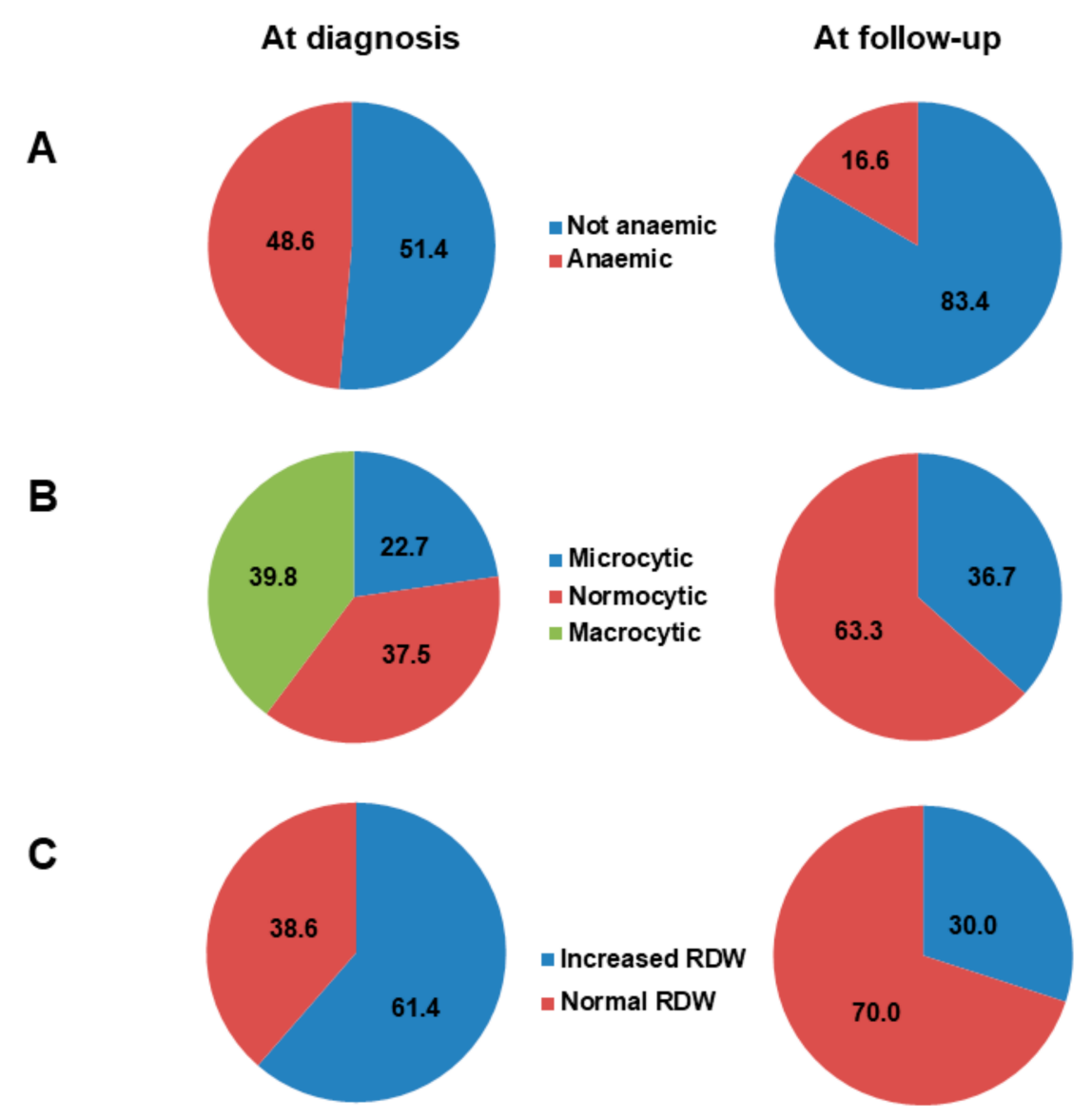

Figure 3. Sub-analysis of a cohort of 181 patients (mean age $59.2 \pm 14.6$ years, female: male ratio $=2.7: 1$ ) who were followed-up for at least one year. The figure shows the proportion of patients with and without 
anaemia at diagnosis and at the one-year follow-up (A), the distribution of mean corpuscular volume $(\mathrm{MCV})$ in anaemic patients at diagnosis and at the one-year follow-up (B), and the distribution of red cell distribution width (RDW) at diagnosis and at the one-year follow-up (C). Abbreviations: RDW, red cell distribution width.

\section{Discussion}

Here we have reported red blood cell alterations in a large cohort of patients with histologically proven AAG at the time of diagnosis. Roughly half of AAG patients were anaemic, being pernicious anaemia and iron deficiency anaemia the most prevalent subtypes, with gender- and age-related differences. Anisocytosis was the strongest predictor of anaemia. Of note, a considerable proportion of non-anaemic AAG patients showed micronutrient deficiencies.

Recently, the clinical burden of anaemia in a number of immune-mediated gastrointestinal disorders, including inflammatory bowel disease and coeliac disease, has gained a great interest $[29,30]$. With regards to AAG, only one study specifically focused on patterns of anaemia and haematologic alterations in biopsy unproven AAG, and only patients who were referred for iron deficiency anaemia or vitamin B12 deficiency were enrolled [6]. In this study, some cases of chronic gastritis without atrophy and active $\mathrm{H}$. pylori infection were also included. Moreover, the prevalence of anaemia and related haematologic alterations in AAG have been described in other series, but only as a part of the general clinical description (see Table 1). Our study reveals that haematologic alterations are the leading reasons for AAG diagnosis. Recently, we have also shown that AAG diagnosis could be delayed partly due to the lack of physician awareness, especially among gastroenterologists, of all possible clinical presentations of this condition [18]. Compared to the presence of overt anaemia, diagnostic delay was longer for scant haematologic alterations ( $<12$ months versus 12-24 months), including isolated microcytosis and macrocytosis. Hence, these subtle alterations should not be overlooked and should prompt further investigations, starting from AAG serological tests [31]. According to previous reports $[7,28,32]$, AAG should be ruled out in all cases of vitamin B12 deficiency and in case of unexplained iron deficiency anaemia. Our data provide further background for supporting this strategy.

Half of AAG patients were anaemic at the time of diagnosis. The crude prevalence of pernicious anaemia was similar to that of iron deficiency anaemia but was different when adjusted for gender and age. Particularly, iron deficiency anaemia was more common in younger female patients, whereas pernicious anaemia was more common in older male patients. These findings may be explained by the slow evolution of AAG, that may take several years to progress $[1,33,34]$. It is reasonable to assume that iron deficiency characterises earlier disease stages, in which hypo-achlorhydria causes iron malabsorption, even if additional unknown immunological factors may have a role. Conversely, vitamin B12 is stored in large amounts and it takes years for pernicious anaemia to develop.

From a pathophysiological point of view, there should be no differences between female and male AAG patients with regard to iron absorption. However, a possible explanation could be that iron deficiency is more likely in women of reproductive age, due to menstrual blood loss. In premenopausal women, menstrual flow per se is a possible confounding factor, frequently causing iron deficiency anaemia, and postmenopausal status is often able to reverse mild anaemia [35]. Data regarding menstrual cycle and menopause were not available, hence no firm conclusion can be drawn in this regard.

The inclusion of patients at different time points of AAG natural history may also explain other findings. Unexpectedly, there seems to be no correlation between anaemia and severity of histological damage, according to both OLGA and OLGIM classifications. Even patients showing severe gastric corpus atrophy might have been enrolled at any time after development of the histological changes. This could also explain the high prevalence of vitamin B12 deficiency, iron deficiency, or a combination of both in patients without anaemia, possibly reflecting the enrolment at an early disease stage. However, mechanisms other than gastric mucosal atrophy could explain our findings. For example, 
the role of other factors, including hypo-achlorhydria, bacterial overgrowth, impairment of iron metabolism, and immunological alterations secondary to AAG still needs to be elucidated.

At multivariate analysis, anisocytosis was the strongest predictor of anaemia. Interestingly, increased RDW has been associated with a higher all-cause mortality rate in the general population [36]. The association of anaemia with the lack of gastrointestinal symptoms is less clear but could reflect a longer diagnostic delay [18] that may favour the occurrence of anaemia. Instead, the association of pernicious anaemia with the lack of $\mathrm{H}$. pylori infection may underlie the pathogenic difference between AAG and post-infectious atrophic gastritis. However, there is still ongoing debate in this regard, with contrasting results [37], and more studies are needed to ascertain this hypothesis. To sum up these results, in clinical practice, the sole presence of anisocytosis should raise the suspicion of AAG, while no other clear predictors were found.

According to the one-year follow-up, most cases of anaemia recovered. Particularly, pernicious anaemia recovered in all cases, while a proportion of patients still had iron deficiency anaemia. These data seem to indicate that iron deficiency anaemia might take more time to recover and oral iron supplementation therapy might fail to restore iron storage adequately.

Some limitations of the study must be mentioned. First, patients might have been diagnosed at different times of AAG natural course, thus affecting the prevalence of haematologic alterations. Also, transferrin and laboratory inflammatory markers were not available in our series. Further, our study did not evaluate the clinical impact of anaemia in terms of disabling symptoms, including fatigue and malaise. Nonetheless, this is the largest cohort of AAG patients that has been described so far, showing that overt anaemia and subtle red blood cell alterations are frequent and are the leading cause of AAG diagnosis.

\section{Conclusions}

More attention should be paid to scant haematologic alterations, most commonly due to vitamin B12 and iron deficiency. Prompt micronutrient supplementation is warranted in AAG patients, as could prevent (or revert) the development of anaemia. Optimal treatment of iron deficiency anaemia still needs to be defined.

Author Contributions: All authors significantly participated in the drafting of the manuscript or critical revision of the manuscript for important intellectual content and provided approval of the final submitted version. Individual contributions are as follow: A.D.S. coordinated and supervised all the participant centres. M.V.L. and E.L. designed and coordinated the study, interpreted data and wrote the manuscript. E.L., L.C., G.B. did statistical analyses. All the other authors interviewed and followed-up patients over time, locally collected data, and reviewed the paper for final approval. A.D.S., B.A., and G.R.C. reviewed the paper and made final critical revision for important intellectual contents.

Acknowledgments: Marco Vincenzo Lenti is grateful to University of Pavia for supporting his research projects.

Conflicts of Interest: The authors declare no conflict of interest.

\section{References}

1. Neumann, W.L.; Coss, E.; Rugge, M.; Genta, R.M. Autoimmune atrophic gastritis: Pathogenesis, pathology and management. Nat. Rev. Gastroenterol. Hepatol. 2013, 10, 529-541. [CrossRef] [PubMed]

2. Di Sabatino, A.; Lenti, M.V.; Giuffrida, P.; Vanoli, A.; Corazza, G.R. New insights into immune mechanisms underlying autoimmune diseases of the gastrointestinal tract. Autoimmun. Rev. 2015, 14, 1161-1169. [CrossRef] [PubMed]

3. Carmel, R. Prevalence of undiagnosed pernicious anemia in the elderly. Arch. Intern. Med. 1996, 156, 1097-1100. [CrossRef] [PubMed]

4. Miceli, E.; Lenti, M.V.; Padula, D. Common features of patients with autoimmune atrophic gastritis. Clin. Gastroenterol. Hepatol. 2012, 10, 812-814. [CrossRef]

5. Massironi, S.; Zilli, A.; Elvevi, A.; Invernizzi, P. The changing face of chronic autoimmune atrophic gastritis: An updated comprehensive perspective. Autoimmun. Rev. 2019, 18, 215-222. [CrossRef] 
6. Hershko, C.; Ronson, A.; Souroujon, M.; Maschler, I.; Heyd, J.; Patz, J. Variable hematologic presentation of autoimmune gastritis: Age-related progression from iron deficiency to cobalamin depletion. Blood 2006, 107, 1673-1679. [CrossRef]

7. Green, R.; Allen, L.H.; Bjørke-Monsen, A.L.; Guéant, J.L.; Miller, J.W.; Molloy, A.M.; Nexo, E.; Stabler, S.; Toh, B.H.; Ueland, P.M.; et al. Vitamin B12 deficiency. Nat. Rev. Dis. Primers 2017, 3, 17040. [CrossRef]

8. Bergamaschi, G.; Di Sabatino, A.; Corazza, G.R. Pathogenesis, diagnosis and treatment of anaemia in immune-mediated gastrointestinal disorders. Br. J. Haematol. 2018, 182, 319-329. [CrossRef]

9. Toh, B.H.; van Driel, I.R.; Gleeson, P.A. Pernicious anemia. N. Engl. J. Med. 1997, 337, 1441-1448. [CrossRef]

10. Lahner, E.; Annibale, B. Pernicious anemia: New insights from a gastroenterological point of view. World J. Gastroenterol. 2009, 15, 5121-5128. [CrossRef]

11. Burman, P.; Karlsson, F.A.; Lööf, L.; Axelsson, C.K.; Szesci, P.B.; Borch, K. $\mathrm{H}^{+}, \mathrm{K}^{+}$-ATPase antibodies in autoimmune gastritis: Observations on the development of pernicious anemia. Scand. J. Gastroenterol. 1991, 26, 207-214. [CrossRef] [PubMed]

12. Lahner, E.; Norman, G.L.; Severi, C.; Encabo, S.; Shums, Z.; Vannella, L.; Delle Fave, G.; Annibale, B. Reassessment of intrinsic factor and parietal cell autoantibodies in atrophic gastritis with respect to cobalamin deficiency. Am. J. Gastroenterol. 2009, 104, 2071-2079. [CrossRef] [PubMed]

13. Lahner, E.; Gentile, G.; Purchiaroni, F.; Mora, B.; Simmaco, M.; Annibale, B. Single nucleotide polymorphisms related to vitamin B12 serum levels in autoimmune gastritis patients with or without pernicious anaemia. Dig. Liver Dis. 2015, 47, 285-290. [CrossRef] [PubMed]

14. Zhang, H.; Jin, Z.; Cui, R.; Ding, S.; Huang, Y.; Zhou, L. Autoimmune metaplastic atrophic gastritis in chinese: A study of 320 patients at a large tertiary medical center. Scand. J. Gastroenterol. 2017, 52, 150-156. [CrossRef] [PubMed]

15. Kalkan, Ç.; Soykan, I. Differences between older and young patients with autoimmune gastritis. Geriatr. Gerontol. Int. 2017, 17, 1090-1095. [CrossRef]

16. Carabotti, M.; Lahner, E.; Esposito, G.; Sacchi, M.C.; Severi, C.; Annibale, B. Upper gastrointestinal symptoms in autoimmune gastritis: A cross-sectional study. Medicine (Baltim.) 2017, 96, e5784. [CrossRef]

17. Villanacci, V.; Casella, G.; Lanzarotto, F.; Di Bella, C.; Sidoni, A.; Cadei, M.; Salviato, T.; Dore, M.P.; Bassotti, G. Autoimmune gastritis: Relationships with anemia and Helicobacter pylori status. Scand. J. Gastroenterol. 2017, 52, 674-677. [CrossRef]

18. Lenti, M.V.; Miceli, E.; Cococcia, S.; Klersy, C.; Staiani, M.; Guglielmi, F.; Giuffrida, P.; Vanoli, A.; Luinetti, O.; De Grazia, F.; et al. Determinants of diagnostic delay in autoimmune atrophic gastritis. Aliment. Pharmacol. Ther. 2019, 50, 167-175. [CrossRef]

19. Lenti, M.V.; Miceli, E.; Padula, D.; Colleoni, R.; Beneventi, F.; Corazza, G.R.; Di Sabatino, A. Infertility and recurrent miscarriage in a patient with autoimmune atrophic gastritis. Intern. Emerg. Med. 2018, 13, 815-816. [CrossRef]

20. Dixon, M.F.; Genta, R.M.; Yardley, J.H.; Correa, P. Classification and grading of gastritis. The updated Sydney System. International Workshop on the Histopathology of Gastritis, Houston 1994. Am. J. Surg. Pathol. 1996, 20, 1161-1181. [CrossRef]

21. Lenti, M.V.; Miceli, E.; Padula, D.; Di Sabatino, A.; Corazza, G.R. The challenging diagnosis of autoimmune atrophic gastritis. Scand. J. Gastroenterol. 2017, 52, 471-472. [CrossRef] [PubMed]

22. Di Sabatino, A.; Biagi, F.; Lenzi, M.; Frulloni, L.; Lenti, M.V.; Giuffrida, P.; Corazza, G.R. Clinical usefulness of serum antibodies as biomarkers of gastrointestinal and liver diseases. Dig. Liver Dis. 2017, 49, 947-956. [CrossRef] [PubMed]

23. Tozzoli, R.; Kodermaz, G.; Perosa, A.R.; Tampoia, M.; Zucano, A.; Antico, A.; Bizzaro, N. Autoantibodies to parietal cells as predictors of atrophic body gastritis: A five-year prospective study in patients with autoimmune thyroid diseases. Autoimmun. Rev. 2010, 10, 80-83. [CrossRef] [PubMed]

24. Rugge, M.; Meggio, A.; Pennelli, G.; Piscioli, F.; Giacomelli, L.; De Pretis, G.; Graham, D.Y. Gastritis staging in clinical practice: The OLGA staging system. Gut 2007, 56, 631-636. [CrossRef] [PubMed]

25. Capelle, L.G.; de Vries, A.C.; Haringsma, J.; Ter Borg, F.; de Vries, R.A.; Bruno, M.J.; van Dekken, H.; Meijer, J.; van Grieken, N.C.; Kuipers, E.J. The staging of gastritis with the OLGA system by using intestinal metaplasia as an accurate alternative for atrophic gastritis. Gastrointest. Endosc. 2010, 71, 1150-1158. [CrossRef] [PubMed]

26. Toh, B.H. Pathophysiology and laboratory diagnosis of pernicious anemia. Immunol. Res. 2017, 65, 326-330. [CrossRef] 
27. WHO. Haemoglobin Concentrations for the Diagnosis of Anaemia and Assessment of Severity. Vitamin and Mineral Nutrition Information System; WHO/NMH/NHD/MNM/11.1; World Health Organization: Geneva, Switzerland, 2011.

28. Hershko, C.; Camaschella, C. How I treat unexplained refractory iron deficiency anemia. Blood 2014, 123, 326-333. [CrossRef]

29. Bergamaschi, G.; Markopoulos, K.; Albertini, R.; Di Sabatino, A.; Biagi, F.; Ciccocioppo, R.; Arbustini, E.; Corazza, G.R. Anemia of chronic disease and defective erythropoietin production in patients with celiac disease. Haematologica 2008, 93, 1785-1791. [CrossRef]

30. Bergamaschi, G.; Di Sabatino, A.; Albertini, R.; Ardizzone, S.; Biancheri, P.; Bonetti, E.; Cassinotti, A.; Cazzola, P.; Markopoulos, K.; Massari, A.; et al. Prevalence and pathogenesis of anemia in inflammatory bowel disease. Influence of anti-tumor necrosis factor-alpha treatment. Haematologica 2010, 95, 199-205. [CrossRef]

31. Miceli, E.; Padula, D.; Lenti, M.V.; Gallia, A.; Albertini, R.; Di Stefano, M.; Klersy, C.; Corazza, G.R. A laboratory score in the diagnosis of autoimmune atrophic gastritis: A prospective study. J. Clin. Gastroenterol. 2015, 49, e1-e5. [CrossRef]

32. Annibale, B.; Capurso, G.; Chistolini, A.; D'Ambra, G.; DiGiulio, E.; Monarca, B.; DelleFave, G. Gastrointestinal causes of refractory iron deficiency anemia in patients without gastrointestinal symptoms. Am. J. Med. 2001, 111, 439-445. [CrossRef]

33. Miceli, E.; Vanoli, A.; Lenti, M.V.; Klersy, C.; Di Stefano, M.; Luinetti, O.; Dominioni, C.C.; Pisati, M.; Staiani, M.; Gentile, A.; et al. Natural history of autoimmune atrophic gastritis: A prospective, single-institution, long-term experience. Aliment. Pharmacol. Ther. 2019, 50, 1172-1180. [CrossRef] [PubMed]

34. Lahner, E.; Zagari, R.M.; Zullo, A.; Di Sabatino, A.; Meggio, A.; Cesaro, P.; Lenti, M.V.; Annibale, B.; Corazza, G.R. Chronic atrophic gastritis: Natural history, diagnosis and therapeutic management. A position paper by the Italian Society of Hospital Gastroenterologists and Digestive Endoscopists (AIGO), the Italian Society of Digestive Endoscopy (SIED), the Italian Society of Gastroenterology (SIGE), and the Italian Society of Internal Medicine (SIMI). Dig. Liver Dis. 2019. [CrossRef]

35. Capurso, G.; Marignani, M.; Delle Fave, G.; Annibale, B. Iron-deficiency anemia in premenopausal women: Why not consider atrophic body gastritis and Helicobacter pylori role? Am. J. Gastroenterol. 1999, 10, 3084-3085. [CrossRef] [PubMed]

36. Patel, K.V.; Ferrucci, L.; Ershler, W.B.; Longo, D.L.; Guralnik, J.M. Red blood cell distribution width and the risk of death in middle-aged and older adults. Arch. Intern. Med. 2009, 169, 515-523. [CrossRef]

37. De Re, V.; Repetto, O.; De Zorzi, M.; Casarotto, M.; Tedeschi, M.; Giuffrida, P.; Lenti, M.V.; Magris, R.; Miolo, G.; Mazzon, C.; et al. Polymorphism in toll-like receptors and Helicobacter pylori motility in autoimmune atrophic gastritis and gastric cancer. Cancers 2019, 11, 648. [CrossRef] 